\title{
Proceeding
}

7th INSHS International Christmas Sport Scientific Conference, 9-12 December 2012. International Network of Sport and Health Science. Szombathely, Hungary

\section{The comparison of maximal and endurance strength of quadriceps femori in trained and untrained elderly}

\author{
PERPARIM FERUNAJ ${ }^{1}$, HARALD TSCHAN ${ }^{2}$ \\ ${ }^{1}$ Sports University of Tirana, Tirana, Albania \\ 2 Faculty of Sport Science, University of Vienna, Austria
}

\begin{abstract}
Ferunaj $\mathrm{P}$, Tschan $\mathrm{H}$. The comparison of maximal and endurance strength of quadriceps femori in trained and untrained elderly. J. Hum. Sport Exerc. Vol.8, No. Proc2, pp. S211-S219, 2013. The purpose of this study was to examine the differences in knee extensor maximal and endurance strength in elderly. Sixteen healthy elderly served as subjects, eight of them trained, age $61.0 \pm 8.9 \mathrm{yrs}$; height, $170.6 \pm 6.8 \mathrm{~cm}$; weight, $71.8 \pm 11.7 \mathrm{~kg}$ [mean \pm standard deviation] and eight untrained $61.4 \pm 8.1 \mathrm{yrs}$, height $174.6 \pm 7.4 \mathrm{~cm}$; weight $83.9 \pm 14.2 \mathrm{~kg}$. Maximal strength in single leg extension exercise was measured unilaterally with the dominant leg until the subjects reached their 1 Repetition Maximum (RM) covering the full Range of Motion (ROM). Muscular endurance was obtained with a load of 75\% of 1-RM for 3 consecutive sets, with 2 min rest periods till failure. Load at $1 \mathrm{RM}$ was lower in absolute terms in untrained, but not significant, while the relative 1-RM test was significantly lower in untrained subjects ( $0.20 \mathrm{vs} .0 .25 \mathrm{~kg}$ load $/ \mathrm{kg}$ body weight) ( $p<$ 0.05). The number of repetitions and amount of weight lifted performed of all 3 sets was higher in trained subjects, but not significant. In the trained group both repetitions and the load managed in the third set was significant lower compared with the first two sets. The result that maximal force output is more affected compared to muscular endurance in these subjects might be due to the habitual use of quadriceps femoris muscles during activity of daily living in both trained and untrained elderly. Key words: KNEE EXTENSORS, RELATIVE 1RM, ABSOLUTE 1RM.
\end{abstract}

Corresponding author. Universiteti i Sporteve. Rr. Muhamet GjolleshaTirana 1001 Tiranë, Albania

E-mail: pferunaj@yahoo.com

7th INSHS International Christmas Sport Scientific Conference, 9-12 December 2012. International Network of Sport and Health Science. Szombathely, Hungary.

JOURNAL OF HUMAN SPORT \& EXERCISE ISSN 1988-5202

(c) Faculty of Education. University of Alicante

doi:10.4100/jhse.2012.8.Proc2.24 


\section{INTRODUCTION}

Aging is associated with natural decrease of both muscular and endurance strength, where most affected from this degenerative process are lower leg muscles. This is well documented from Petrella and his partners (Petrella et al., 2005), where the authors observed that the older adults showed significantly lower leg extensor strength compared to their younger counterparts. In addition, one study made by Rogers and Evans (1993) showed an approximate 30\% decline in muscle strength and a 40\% reduction in muscle area between the second and seventh decades of life. Thus, the loss of muscle mass with aging appears to be the major factor in the age-related loss of muscle strength. Moreover, considering that most of the loss happen to types 2 fibers, as Rogers and Evans (1993) demonstrated, old people find it difficult to carry out daily activities of high requirements to rate of force development.

However, if older adults continue to use their muscles during aging, they can minimise this process. Jones and Rose (2005) assume that resistance training has significant impact on the quality of life and physical function of older adults. The importance of muscular strength of lower extremities in elderly has been investigated by numerous researchers, not just for maximal performance per se, but for improving simple functions (e.g., climbing stairs or standing from a chair). The association between muscular strength and functional performance in elderly is mutual. Thus, Sallinen et al., (2007) reported that strength training has positive health effects for aging men by increasing maximal strength and functional performance, and by decreasing the resting blood pressure. However, the natural decrease of muscular size and related strength during aging is inevitable, despite of the training status. Aging does not affect only general population regarding the decrease of muscular strength. According to Meltzer (1993), weight lifting performance in master athletes declines with age at an average rate between 1.0 to $1.5 \%$ per year until approximately the age of 70 , after which the rate increases much more pronounced. Indeed, the similar decline regarding muscle power and isometric strength between elite masters weightlifting and agedmatched, healthy untrained individuals was observed in a study by (Person et al., 2002), but the same study demonstrated that muscle power of 85 years old weightlifting master was the same as 65 years old non training individual. Considering these data, it is evident the advantage of training status within the same age.

When comparing the muscular strength between trained and untrained individuals, both maximal and muscular endurance (endurance strength) need to be assessed. Expressing maximal strength is the most important characteristic of Olympic weightlifting sport, and taking this into consideration, we can assume that trained subjects of our study have higher $1 \mathrm{RM}$ in leg extension exercise, although this exercise is not included in the routine of weightlifting training program. Considering the muscular endurance, some investigators report that trained individuals are able to perform the same, (Kraemer et al., 1999) or a greater (Braith et al., 1993; Hoeger et al., 1990; Pick \& Becque, 2000) number of repetitions at a given exercise intensity than untrained subjects.

The work of lower leg muscles, where the most important are knee extensors such as quadriceps femori, is vital to perform proper walking in elderly. Due to the importance of this muscle group, research has always focused on leg extension exercise in measuring muscular strength in all groups of subjects including the elderly. Fiatarone et al. (1994) provided evidence that improvement in quadriceps femoris and hip extensors muscle strength resulted in improved gait velocity and stair climbing ability. However, another study from Carmeli and his partners (Carmeli et al., 2000) reported that the improvement in functional abilities did not correlate with muscle strength, body weight, or body fat. Training status is not only factor of differences in muscular strength in elderly. Another factor is gender. It seems that older men are less lucky 
than opposed sex counterparts, when speaking for muscle mass, and consequently, muscle strength. Gallagher et al. (1997) found that gender greatly influenced muscle mass and that, with advancing age, men experience a decline in muscle mass almost twice that of women. In addition, Metter et al. (1997) reported that men had greater rates of strength decline than women, and that increasing age was associated with greater loss of strength.

The primary aim of the current study was: to investigate the differences on maximal and endurance strength between former weightlifters and age-matched healthy sedentary individuals.

\section{MATERIAL AND METHODS}

\section{Participants}

Subjects for this study were eight trained (T) and eight untrained older men (UT). Physical characteristics of the subjects (trained and untrained) are presented in table 1. T-Test analysis showed that untrained subjects were heavier than trained, but not significant.

Participants for this study were recruited from a local sporting club in Tirana (Albania) and through advertisement at a senior club of the same city. Subjects received medical clearance from a physician before participating in the study and had to report their lifetime physical activity. Subjects were excluded if they suffered from any serious medical conditions, including uncontrolled heart, respiratory or knee problems. In the training group only former weightlifters being still physical active on a regularly basis, performing strength training at least 2 times a week, were enrolled in this study. Untrained subjects were matched to age and had not been involved in a formal resistance weight-training program previously. All details of the study were explained to each subject and all participants gave written informed consent for their participation in the study. All exercise testing sessions were completed at a gym located in Tirana City.

Table 1. Physical characteristics of the subjects

\begin{tabular}{ccc}
\hline Variable & Trained Subjects $(\mathbf{n}=\mathbf{8})$ & Untrained Subjects $(\mathbf{n}=\mathbf{8})$ \\
\hline Age $($ years $)$ & $61.0 \pm 8.9$ & $61.4 \pm 8.1$ \\
Weight $(\mathrm{kg})$ & $71.8 \pm 11.7$ & $83.9 \pm 14.2$ \\
Height $(\mathrm{cm})$ & $170.6 \pm 6.8$ & $174.6 \pm 7.4$ \\
BMl $\left(\mathrm{kg} / \mathrm{m}^{2}\right)$ & $24.6 \pm 3.1$ & $27.5 \pm 4.3$ \\
Waist Circumference $(\mathrm{cm})$ & $85.9 \pm 6.5$ & $103.6 \pm 22.0$ \\
Thigh Circumferences $(\mathrm{cm})$ & $47.7 \pm 6.0$ & $53.7 \pm 10.8$ \\
Thigh Fat $(\mathrm{mm})$ & $17.2 \pm 3.0$ & $21.3 \pm 4.9$ \\
\hline
\end{tabular}

\section{Methodology}

Subject's standing height was measured in $\mathrm{cm}$ using height gauge to the nearest $0,5 \mathrm{~cm}$ and body mass with a "Balance Exacta" (Soenhle-Leifheit Group, Murrhart, Germany) in light indoor clothing without shoes. 
Strength measurements were performed on a leg extension device (Panatta Sport, Apiro, Italy). Actually single leg extension exercise (as single-joint) exercise was chosen, because it has been shown to pose minimal risk of injury due to the reduced level of skill and technique involved. While a test of 1-RM of seated knee extension can be used in exercise prescription, it may be more accurate to apply optimal load in an isolated exercise compared to a more complex exercise. In addition, we have chosen knee extension as the outcome variable because it correlates with functional capacity deficits (Rantanen et al., 1994), morbidity (Luukinen et al., 1997), and mortality (Laukkanen et al., 1995) in sarcopenic older adults. It is well known from fitness and conditioning coaches that proper technical execution of knee extension requires both concentric and eccentric contraction performed with full Range of Motion (ROM). Several training studies have demonstrated that dynamic muscular strength and morphological changes in muscle have been greatest when both $\mathrm{CON}$ and ECC actions are used in a resistant training program (Colliander \& Tesch, 1990; Dudley et al., 1991; O'Hagan et al., 1995). Furthermore, open-chain testing like leg extension is heavily used in research and rehabilitation evaluation.

\section{Resistance Exercise Measurement Procedures}

Assessment was divided into two days; First day we measured 1-RM testing in single leg extension with dominant leg, and next day muscle endurance using $70-75 \%$ of the 1-RM. After the warm-up sets, subjects rested 3-5 minutes, and then were tested for 1RM strength using proper technique through a full range of motion. On verbal command, the subject performed a maximum knee extension with the dominant leg. The highest weight lifted was recorded as the 1RM value.

Because of the exhaustive nature of the endurance test, it was performed at the second day when each subject performed a test of local muscular endurance on the leg extension exercise. Following a warm-up set of 6 repetitions with a relatively light load of about $50 \%$ of 1-RM (and a 2-minute rest period thereafter), subjects attempted to perform as many repetitions as possible with $70-75 \%$ of the 1-RM (in most cases 5 $\mathrm{kg}$ less than their individual 1-RM). The participants were tested in 3 consecutive sets, with a 2-minute rest period between. During each set, subjects were verbally encouraged to perform as many repetitions as possible.

\section{Statistics}

Statistic 6.0 software package was used to perform Descriptive Statistics. The physical characteristics of the subjects were compared using an independent samples t-test. Significance was accepted at $P<0.05$. The Mann-Whitney test was used to identify differences between trained and untrained subjects. Repeated measurement ANOVA was performed to compare the different sets during the muscle endurance test Tukey post-hoc test was performed to evaluate whether differences between any two pairs of means are significant

\section{RESULTS}

Table 2 summarizes absolute and relative 1-RM performed in single leg extension exercise. The table also gives the number of repetitions (mean $\pm \mathrm{SD}$ ) performed, during 3 consecutive sets, and for each set, with $70-75 \%$ of 1 RM and total weight lifted in all 3 sets. There were no significant $(p<0.05)$ differences for 1 RM absolute and total volume (number of repetitions), or weight lifted for all 3 sets between trained and untrained groups. However, a significant difference $(p<0.05)$ was found for 1 RM adjusted to body mass. The subjects could complete more repetitions at first set compared with second and third set. 
Table 2. Muscle strength comparison between untrained (UT) and trained (T) Subjects

\begin{tabular}{ccc}
\hline Variable & $\begin{array}{c}\text { Untrained } \\
(\mathbf{n}=\mathbf{8})\end{array}$ & Trained $(\mathbf{n}=\mathbf{8})$ \\
\hline & & \\
1 RM absolute $(\mathrm{kg})$ & $17.18 \pm 3.64$ & $18.75 \pm 5.17$ \\
1 RM relative $(\mathrm{kg} / \mathrm{BM}){ }^{*}$ & $\mathbf{0 . 2 0 \pm 0 . 0 4}{ }^{*}$ & $\mathbf{0 . 2 5} \pm \mathbf{0 . 0 4}$ \\
Total volume (no of rep) & $24.37 \pm 6.09$ & $26.12 \pm 7.14$ \\
Number of repetitions (set 1) & $9.62 \pm 2.44$ & $9.50 \pm 3.16$ \\
Number of repetitions (set 2) & $7.75 \pm 2.60$ & $9.12 \pm 2.53$ \\
Number of repetitions (set 3) & $7.00 \pm 3.89$ & $7.50 \pm 1.92 \dagger$ \\
Weight lifted in all 3 sets (kg) & $289 \pm 88.17$ & $348.12 \pm 79.05$ \\
\hline
\end{tabular}

\section{Absolute muscle strength}

T-Test analysis showed the comparisons of maximal muscular strength or 1 Repetition Maximum (1 RM) on the absolute score basis (i.e., total force in $\mathrm{kg}$ ) not taking into consideration the body mass (Fig. 1). The results indicate that trained subjects $(T)$ of group 1, possess greater strength than untrained (UT) of group 2 , for single leg extension (18.75 $\pm 5.17 \mathrm{~kg}$ vs. $17.18 \pm 3.64 \mathrm{~kg}$ ). The untrained score about $9 \%$ lower than trained for maximal strength. This disparity generally coincides with cross sectional area of quadriceps muscle (not measured in our study), which we hypotheses that in trained subject is greater. Exceptions were observed in former weightlifters who have trained for years with progressive resistance exercise to develop specific muscle groups and more focused in leg extensor.

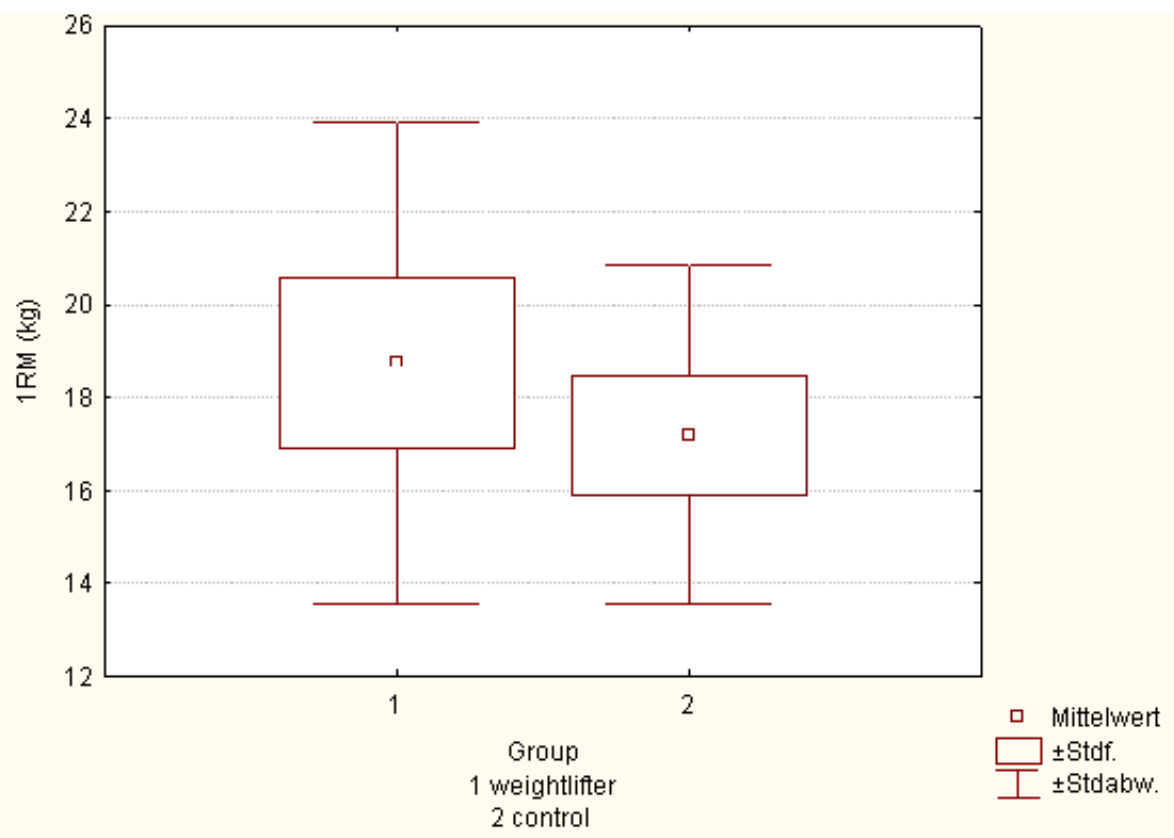

Figure 1. 1RM in single leg extension. Weightlifters vs control 
Relative muscle strength

In our test (Fig. 2), relative muscle strength (adjusted to body mass) in the weightlifting group was significantly higher $(p<0.05)$ than the untrained group $(0.25 \pm 0.04$ vs. $0.20 \pm 0.04)$. These facts indicated that relative muscle strength (1 RM /Body Mass), which represents the quality of the muscles, is related to training status.

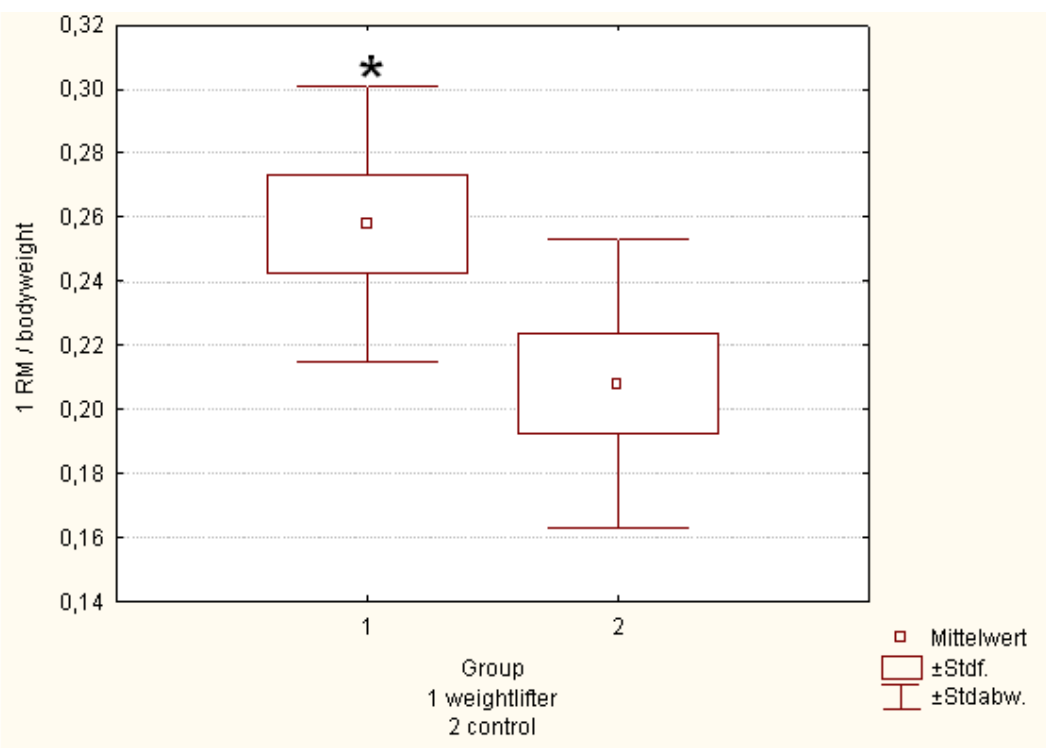

Figure 2. 1RM / bodyweight leg extension. Weightlifters vs control

\section{Muscular Endurance}

Muscular endurance, expressed in number of repetitions (Fig. 3) of all 3 sets between two groups is not different [26.12 \pm 7.14 (T) vs. $24.37 \pm 6.09$ (UT)], whereas weightlifting volume expressed in kg. (Fig. 4) was higher in Trained Group (27\%), but not significant (348.12 kg vs. $289.06 \mathrm{~kg}$ ).

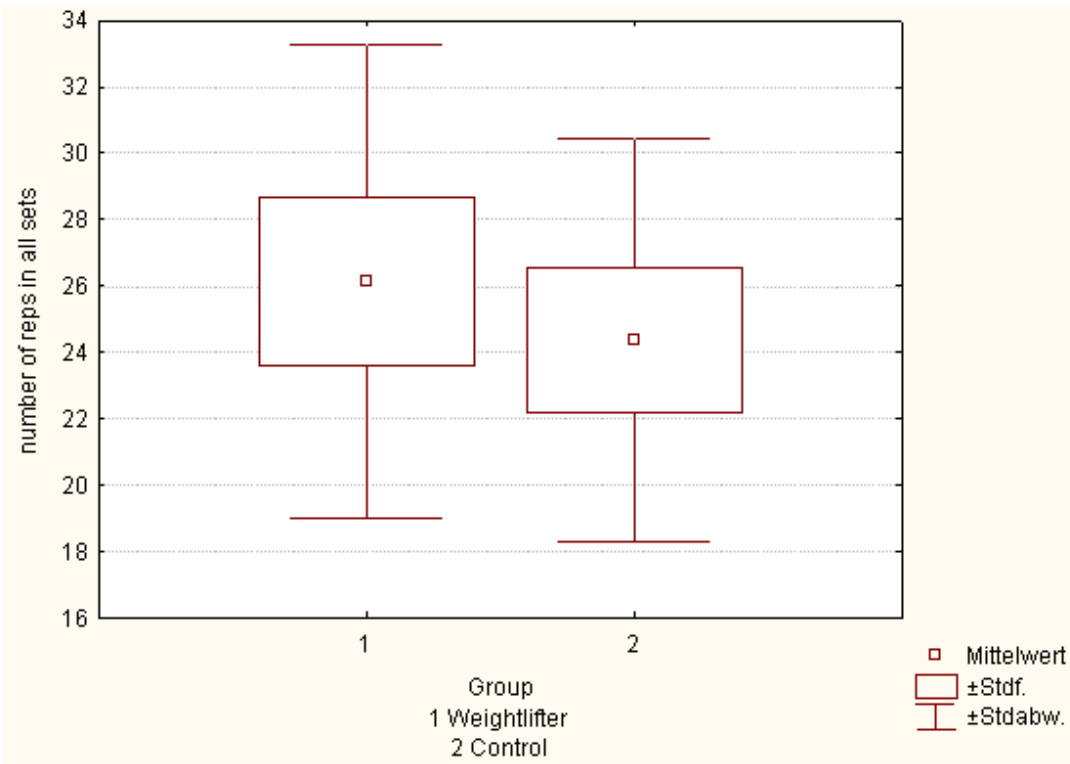

Figure 3. Muscular endurance expressed in number of repetitions 


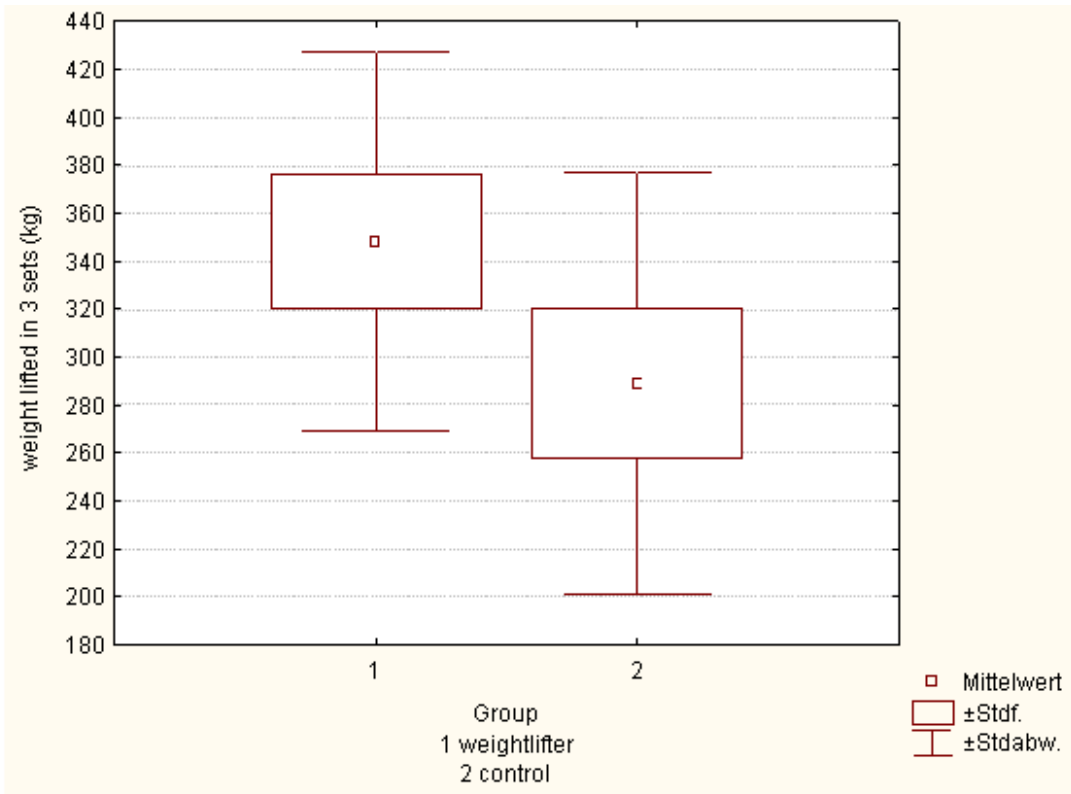

Figure 4. Muscular endurance expressed in total $\mathrm{kg}$ for all 3 sets

\section{DISCUSSION AND CONCLUSIONS}

The data gathered from this study showed that the 1-RM adjusted to body weight represents a primary difference between untrained and trained. Another study from Leong et al.,(1999) showed that maximal firing frequency obtained in the rectus femoral muscle during maximal voluntary contraction (MVC) was $20 \%$ greater in trained elderly weight lifters, compared to age-matched untrained individuals.

The lack of difference in absolute knee extension strength in the untrained subjects compared to the trained might be explained by the training effect of weight bearing and support of a larger body mass. However when the dependent effect of body mass is included, (relative strength) these strength measures, turned out to be lower in untrained elderly. In a recent study by Sallinene et al., (2007) authors also measured significant differences in strength (isometric using a dynamometer) of master strength athletes - compared to sedentary control. However, contrary to our study, in this paper, also absolute measures differed significantly $(p<0.01)$.

The facts from our results showed that muscular endurance is dependent on maximal strength. Thus, the increase of $1 \mathrm{RM}$ in T group is associated with the increased number of repetitions.

Without doubt, trained elderly showed a greater muscular strength because of their larger initial muscular strength, and because they were still active exercising on a regular basis when tested for their strength. Moreover, it is well known that the increase of 1-RM is the most important aim in weightlifting sport, and this is in line with our findings of differences of 1 RM between trained and untrained. Other factors, such as the pennation of muscle fibbers, can be the answer of discerapities in maximal strength between trained and untrained elderly. Thus, a study from Reeves et al., (2004) found the resting fibre pennation angle of the Vastus Lateralis (VL) was increased by 28-35\%, according to the knee joint angle, after 14 weeks of High Resistance Strength Training (HRST). In addition, neural factors can be the superior advantage of trained 
subjects. Thus, one study from differences in neural activation between T an UT may contribute to higher 1 RM performance, as suggested by Leong et al., (1999).

In conclusion, the results of the present study has shown that the primary difference between trained and untrained elderly subjects regarding two muscular determinants (1-RM and muscular endurance) for a unilateral leg extension exercise is the higher 1-RM adjusted to body weight (Relative strength) in trained subjects. When looked at in absolute terms, the data in the present study show that master weightlifters are not considerably stronger than their counterparts. Considering the muscular endurance no differences were noted between two groups. These data suggest that the weight bearing effect for both untrained and trained subjects can be a factor for lack of difference concerning the number of repetitions. However, the facts that the amount of weight lifted in all 3 consecutive sets is higher in master weight lifters group, partly reflects that the muscular endurance is linked to the $1 \mathrm{RM}$. The data presented here suggest that activities which require high levels of muscle strength repetitively like in weightlifting exercises may help improve or maintain muscle function in later life

\section{REFERENCES}

1. BRAITH, RW, GRAVES JE, LEGGETT SH, POLLOCK ML. Effect of training on the relationship between maximal and submaximal strength. Med Sci Sports Exerc. 1993; 25(1): 132-138.

2. CARMELI E, REZNICK AZ, COLEMAN R, CARMELI V. Muscle strength and mass of lower extremities in relation to functional abilities in elderly adults. Gerontology. 2000; 46(5): 249-57.

3. COLLIANDER E, TESCH PA. Effects of eccentric and concentric muscle actions in resistance training. Acta Physiol Scand. 1990; 140(1): 31-9.

4. DUDLEY GA, TESCH PA, MILLER BJ, ET AL. Importance of eccentric actions in performance adaptations to resistance training. Aviat Space Environ Med. 1991; 62(6): 543-50.

5. FIATARONE MA, O'NEILL EF, RYAN ND, CLEMENTS KM, SOLARES GR, NELSON ME, ROBERTS SB, KEHAYIAS JJ, LIPSITZ LA, EVANS WJ. Exercise training and nutritional supplementation for physical frailty in very elderly people. N Engl J Med. 1994; 23; 330(25): 17691775.

6. GALLAGHER D, RUTS E, VISSER M, HESHKA S, BAUMGARTNER RN, WANG J, PIERSON RN, PI-SUNYER FX, HEYMSFIELD SB. Weight stability masks sarcopenia in elderly men and women. Am. J. Physiol. Endocrinol. Metab. 2000; 279: E366-E375.

7. HOEGER W, HOPKINS DR, BARETTE SL, HALE DF. Relationship between repetitions and selected percentages of one repetition maximum: A comparison between untrained and trained males and females. J. Appl. Sport Sci. Res.1990; 4(2): 47-54.

8. JESSIE JONES G, ROSE DJ.Resistance training. Physical Activity instructions of older adults. New Zeeland: Human Kinetics, 2005.

9. KRAEMER WJ, FLECK SJ, MARESH CM, RATAMESS NA, GORDON SE, GOETZ KL, HARMAN EA, FRYKMAN PN, VOLEK JS, MAZZETTI SA, FRY AC, MARCHITELLI LJ, PATTON JF. Acute hormonal responses to a single bout of heavy resistance exercise in trained power lifters and untrained men. Can J Appl Physiol. 1999; 24(6): 524-537.

10. LAUKKANEN P, HEIKKINEN E, KAUPPINEN M. Muscle strength and mobility as predictors of survival in 75-84-year-old people. Age Ageing. 1995; 24(6): 468-473.

11. LEONG B, KAMEN G, PATTEN C, BURKE J. Maximal motor unit discharge rates in the quadriceps muscles of older weight lifters. Med Sci Sports Exerc. 1999: 31(11): 1638-1644. 
12. LINDLE RS, METTER EJ, LYNCH NA, FLEG JL, FOZARD JL, TOBIN J, ROY TA, HURLEY BF. Age and gender comparisons of muscle strength in 654 women and men aged 20-93 yr. J Appl Physiol. 1997; 83(5): 1581-1587

13. LUUKINEN H, KOSKI K, LAIPPALA P, KIVELA SL. Factors predicting fractures during falling impacts among home-dwelling older adults. J Am Geriatr Soc. 1997; 45(11): 1302-1309.

14. MELTZER DE. Age dependence of Olympic weightlifting ability. Med Sci Sports Exerc. 1994; 26(8): 1053-1067.

15. METTER EJ, CONWIT R, TOBIN J, FOZARD JL. Age-associated loss of power and strength in the upper extremities in women and men. J Gerontol Biol Sci. 1997; 52A(5): B267-B276.

16. O'HAGAN FT, SALE DG, MACDOUGALL JD, GARNER SH. Comparative effectiveness of accommodating and weight resistance training modes. Med Sci Sports Exerc 1995; 27(8): 1210-9

17. PEARSON SJ, YOUNG A, MACALUSO A, DEVITO G, NIMMO MA, COBBOLD M, HARRIDGE SD. Muscle function in elite master weightlifters. Med Sci Sports Exerc. 2002; 34(7): 1199-1206.

18. PETRELLA JK, KIM JS, TUGGLE SC, HALL SR, BAMMAN MM. Age differences in knee extension power, contractile velocity, and fatigability. J Appl Physiol 2005; 98(1): 211-220.

19. PICK J, BECQUE MD. The relationship between training status and intensity on muscle activation and relative submaximal lifting capacity during the back squat. J Strength Cond Res. 2000; 14(2): 175-181.

20. RANTANEN T, ERA P, HEIKKINEN E. Maximal isometric strength and mobility among 75-year-old men and women. Age Ageing. 1994; 23(2): 132-137.

21. REEVES ND, NARICI MV, MAGANARIS CN. Effect of resistance training on skeletal muscle muscle specific force in elderly humans. J Appl Physiol. 2004; 96(3): 885-92-

22. ROGERS, MA, EVANS, WJ. Changes in skeletal muscle with aging: effects of exercise training. Exerc Sport Sci Rev. 1993; 21: 65-102.

23. SALLINEN J, FOGELHOLM M, VOLEK JS, KRAEMER WJ, ALEN M, HÄKKINEN K. Effects of strength training and reduced training on functional performance and metabolic health indicators in middle-aged men. Int J Sports Med. 2007; 28(10): 815-22.

24. TUDOR-LOCKE C, JOHNSON WD, KATZMARZYK PT. Frequently reported activities by intensity for U.S. adults: the American time use survey. American Journal of Preventive Medicine. 2010; 39(4): E13-E20. 